\title{
EARTH SURFACE DEFORMATION OF THE SAKHALIN ISLAND FROM GPS DATA
}

\author{
A. S. Prytkov, N. F. Vasilenko \\ Institute of Marine Geology and Geophysics, Far East Branch of RAS, Yuzhno-Sakhalinsk, Russia
}

\begin{abstract}
The earth surface deformation was modeled for the North, Central and South Sakhalin on the basis of deformation velocities recorded by the GPS stations of the Sakhalin Geodynamical Network. A pattern of contemporary horizontal deformation is intricate in the vicinity of the main submeridional faults of the island. On the island surface, the dominant deformation regime is compression; however, the spatial distribution of deformation is heterogeneous. The horizontal compression is mainly sublatitudinal and SW-NE-trending. In addition to compression, there are zones of rather intense right-lateral strike-slip in the northern and central parts of the island, while stretching dominates in the south-eastern parts. The regional geodynamic setting is reflected in the seismicity of the island. Recently, the seismic activity has been increased in the areas characterized by intensive surface deformation, while the areas of low deformation rates correlate with the zones of weak and sparse seismicity.
\end{abstract}

Key words: contemporary crustal movement; GPS observations; deformation; Sakhalin Island

\section{RESEARCH ARTICLE}

Handling Editor: V.A. Sankov
Received: March 23, 2018

Revised: May 16, 2018

Accepted: May 31, 2018

For citation: Prytkov A.S., Vasilenko N.F., 2018. Earth surface deformation of the Sakhalin Island from GPS data. Geodynamics \& Tectonophysics 9 (2), 503-514. doi:10.5800/GT-2018-9-2-0358.

Для цитирования: Прытков А.C., Василенко Н.Ф. Деформации земной поверхности острова Сахалин по данным GPS-наблюдений // Геодинамика и тектонофизика. 2018. Т. 9. № 2. С. 503-514. doi:10.5800/GT-2018-9-2-0358. 


\title{
ДЕФОРМАЦИИ ЗЕМНОЙ ПОВЕРХНОСТИ ОСТРОВА САХАЛИН ПО ДАННЫМ GPS-НАБЛЮДЕНИЙ
}

\author{
А. С. Прытков, Н. Ф. Василенко
}

Институт морской геологии и геофизики ДВО РАН, Южно-Сахалинск, Россия

\begin{abstract}
Аннотация: На основе GPS-скоростей пунктов Сахалинской геодинамической сети выполнено моделирование деформированного состояния земной поверхности северной, центральной и южной части о. Сахалин. Полученные данные показывают сложную картину современных горизонтальных деформаций в окрестностях главных субмеридиональных разломов острова. Преобладающим деформационным режимом является сжатие островной суши, однако пространственное распределение деформаций неоднородно. Сокращение земной коры происходит в основном в субширотном и ЮЗ-СВ направлениях. Наряду со сжатием на севере и в центре острова выделяются области достаточно интенсивных деформаций правостороннего сдвига, в юговосточной части острова преобладают деформации растяжения. Региональная геодинамическая обстановка находит отражение в сейсмичности острова. В районах интенсивного деформирования земной поверхности проявляется повышенная сейсмическая активность последних лет, тогда как области низких скоростей деформаций коррелируют с зонами слабой и разреженной сейсмичности.
\end{abstract}

Ключевые слова: современные движения земной коры; GPS-наблюдения; деформация; остров Сахалин

\section{1. ВВЕДЕНИЕ}

Современная геодинамика о. Сахалин определяется взаимодействием Евразийской (Амурской) и Североамериканской (Охотской) литосферных плит. Граница плит обычно отождествляется с системой главных субмеридиональных разломов острова: Хоккайдо-Сахалинского, Центрально-Сахалинского и Западно-Сахалинского [Chapman, Solomon, 1976; Zonenshain, Savostin, 1981; Vasilenko, Prytkov, 2012]. Скорость конвергенции литосферных плит в различных геодинамических моделях увеличивается с севера на юг, достигая в пределах островной суши 10-13 мм/год по азимуту $250^{\circ}$ [Altamimi et al., 2002; Apel et al., 2006; DeMets et al., 2010; Kogan, Steblov, 2008]. Схождение литосферных плит проявляется в интенсивном неоднородном деформировании земной коры и высокой сейсмической активности региона [Poplavskaya et al., 2006; Konovalov et al., 2016; Federal Research Centre..., 2017].

Напряженно-деформированное состояние недр острова является отражением характера современных тектонических процессов в регионе. Реконструкция напряжений и деформаций необходима для определения внутренних особенностей строения земной коры и обоснованного выделения областей возможных очагов землетрясений.

Основным источником сведений о напряженнодеформированном состоянии являются данные о механизмах очагов землетрясений. Его детальному исследованию посвящены работы [Konovalov et al., 2014; Sim et al., 2017a, 2017b; Tataurova, 2015], в которых выполнена реконструкция напряжений и деформаций на основе современной сейсмичности о. Сахалин. Показано, что территория острова в целом характеризуется субширотным сжатием, что соответствует современному тектоническому режиму региона. Однако вариации упругих напряжений прослеживаются на всем простирании острова: субширотное сжатие на юге сменяется диагональным сжатием ЮЗ-СВ направления в центральной и северной части [Konovalov et al., 2014], а выявленные области растяжений можно считать откликом среды на общее региональное сжатие [Tataurova, 2015].

Обобщенный анализ новейшей тектоники с реконструкцией тектонических напряжений показал доминирование на острове напряженного состояния сдвигового типа с субгоризонтальными осями сжатия и растяжения. Оси сжатия ориентированы субширотно, растяжения - субмеридионально. Такой комплексный анализ позволил откартировать районы с различной геодинамической обстановкой [Sim et al., 2017a, 2017b].

Дополнительным источником информации о напряженно-деформированном состоянии являются данные о скоростях смещений земной поверхности, которые также отражают процессы, протекающие в земной коре. В последние годы основным 
методом их изучения являются спутниковые GPS/ГЛОНАСС измерения. В отличие от других методов, геодезические данные не только позволяют отслеживать изменение деформированного состояния в пространстве, но и дают количественные оценки современных деформационных процессов.

Для территории о. Сахалин общая оценка горизонтальных деформаций, по данным о скоростях смещений земной поверхности, сделана в работе [Ashurkov et al., 2016]. Установлено, что скорость сжатия островной суши достигает $-35 \times 10^{-9}$ в год. Направление осей сжатия плавно изменяется от 3СЗ-ВЮВ на юге до ВСВ-ЗЮЗ на севере острова. Однако эти результаты не отражают всех особенностей современной геодинамики острова, так как получены на основе малого количества исходных данных.

В настоящей работе на основе межсейсмических горизонтальных скоростей пунктов Сахалинской геодинамической GPS-сети, свободных от влияния косейсмических смещений от местных и удаленных землетрясений, выполнена детальная оценка деформированного состояния земной поверхности северной, центральной и южной части о. Сахалин.

\section{2. АКТИВНЫЕ РАЗЛОМЫ И СЕЙСМИЧНОСТЬ О. САХАЛИН}

Для анализа сейсмичности о. Сахалин построена карта эпицентров землетрясений с $\mathrm{M} \geq 3.0$ за период 1905-2016 гг. (рис. 1, a). В основу карты легли данные регионального каталога землетрясений за период 1905-2005 гг. [Poplavskaya et al., 2006], а также результаты детальных сейсмологических наблюдений последних лет на севере [Konovalov et al., 2016] и юге острова [Federal Research Center..., 2017].

Сейсмичность острова отличается неоднородным распределением эпицентров землетрясений, гипоцентры которых в основном сосредоточены в земной коре на глубинах до 20 км. Выделяются три района - южный, центральный и северный - с наибольшим числом событий, разделенных участками с редкими эпицентрами сравнительно слабых землетрясений. На севере острова наибольшая концентрация землетрясений наблюдается вдоль северо-восточного побережья, в то время как в центральной и южной части повышенная активность приурочена к западному побережью. Между тем в центральной и южной части острова отчетливо прорисовываются области пониженной сейсмичности, которые, по мнению О.А. Мельникова [Melnikov, 1977], связаны с древними (мел-палеогеновыми) видоизмененно-реликтовыми антиклинориями.
Характерной особенностью сейсмичности острова является ее тесная связь с тектонической активностью главных субмеридиональных разломов и их оперений. В земной коре Сахалина и окружающих его акваторий выделяются три основных системы активных разломов: Хоккайдо-Сахалинская, Центрально-Сахалинская и Западно-Сахалинская.

Хоккайдо-Сахалинская зона представлена субмеридиональной взбросо-сдвиговой системой разломов, протягивающейся вдоль восточного побережья острова. К этой зоне разломов приурочено Нефтегорское межплитовое землетрясение 1995 г., $\mathrm{M}=7.1$, в результате которого вскрылся ВерхнеПильтунский сейсморазрыв, и серия умеренных сейсмических событий с $\mathrm{M}=5.0-6.0$.

Центрально-Сахалинский разлом пересекает практически весь остров - от южной конечности до широты $51.5^{\circ}$ на севере. Кинематика разлома в целом характеризуется взбросо-надвиговой природой. За инструментальный период наблюдений сейсмическая активность разломной зоны невысока. Однако по результатам палеосейсмологических исследований разлом способен генерировать землетрясения с M=7.0-7.5 [Streltsov, Kozhurin, 2002].

Западно-Сахалинская разломная зона вытянута вдоль восточного побережья Татарского пролива и проявляется в виде тесно связанных между собой сбросов и взбросов. Сейсмическая активность этой разломной зоны достаточно высока. В ее пределах наблюдалось несколько сильных землетрясений, в том числе Углегорское 2000 г., М=7.0, и Невельское 2007 г., $\mathrm{M}=6.2$.

\section{3. РЕЗУЛЬТАТЫ GPS-НАБЛЮДЕНИЙ}

Для изучения современной геодинамики о. Сахалин в 1999-2003 гг. на юге, в центральной части и на севере острова были созданы региональные сети периодических GPS-наблюдений (рис. 2, $a, 3, a$, $4, a)$, которые вошли в состав Сахалинской геодинамической сети [Vasilenko et al., 2016]. Геодезические сети представляют собой поперечные профили, пересекающие островную сушу с запада на восток. Такая геометрия сетей определялась из тектонических особенностей региона, а сгущение на севере и юге острова продиктовано необходимостью оценки относительных смещений отдельных структурных элементов.

К 2013 г. на объектах проведены 4-6 повторных эпох измерений продолжительностью не менее трех суток на каждом пункте наблюдений. Для минимизации сезонного влияния на точность позиционирования все полевые измерения проводились в летне-осенний период, при этом на пунктах использовались те же GPS-антенны, что и в 
(a)

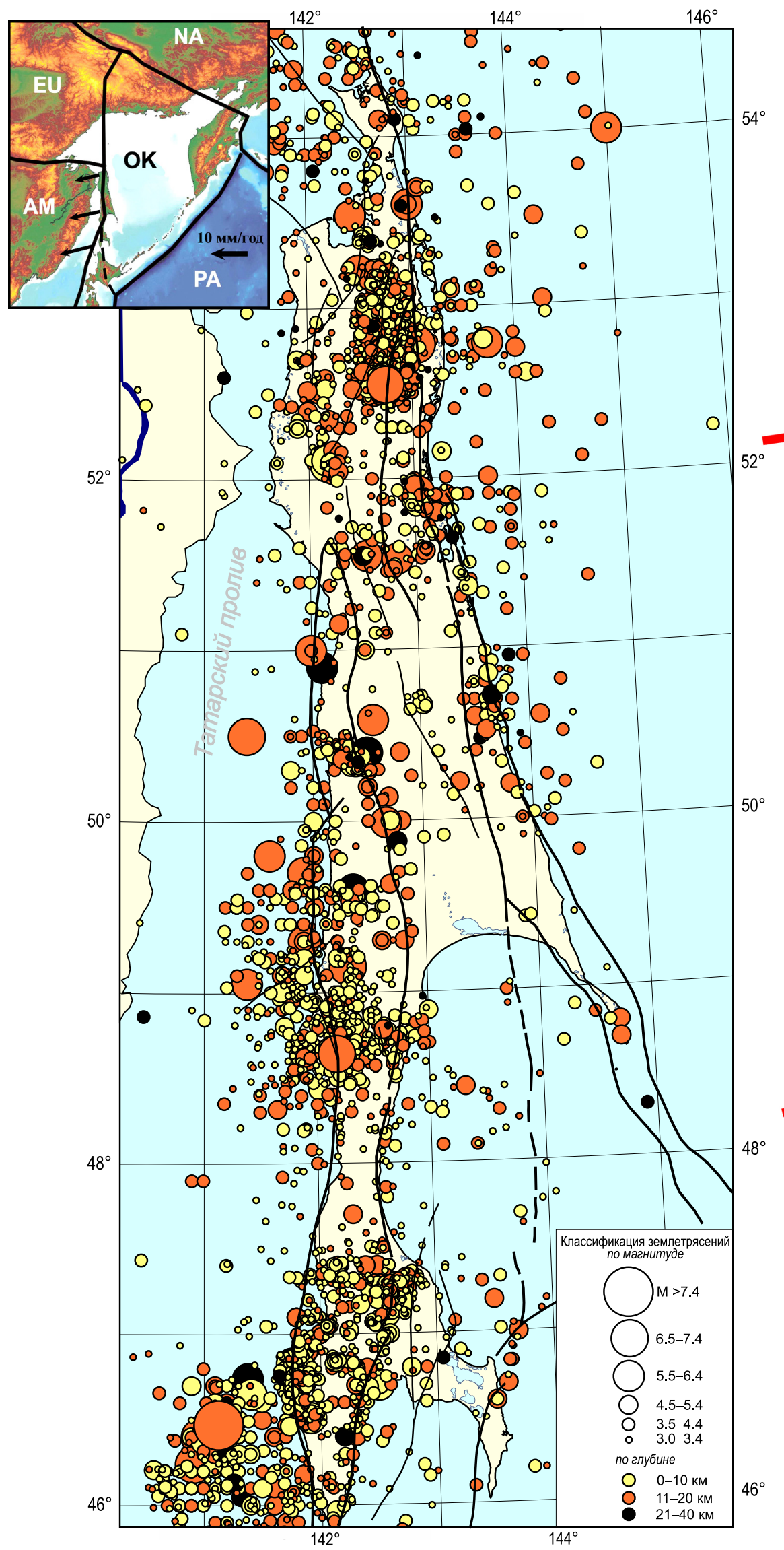

(б)

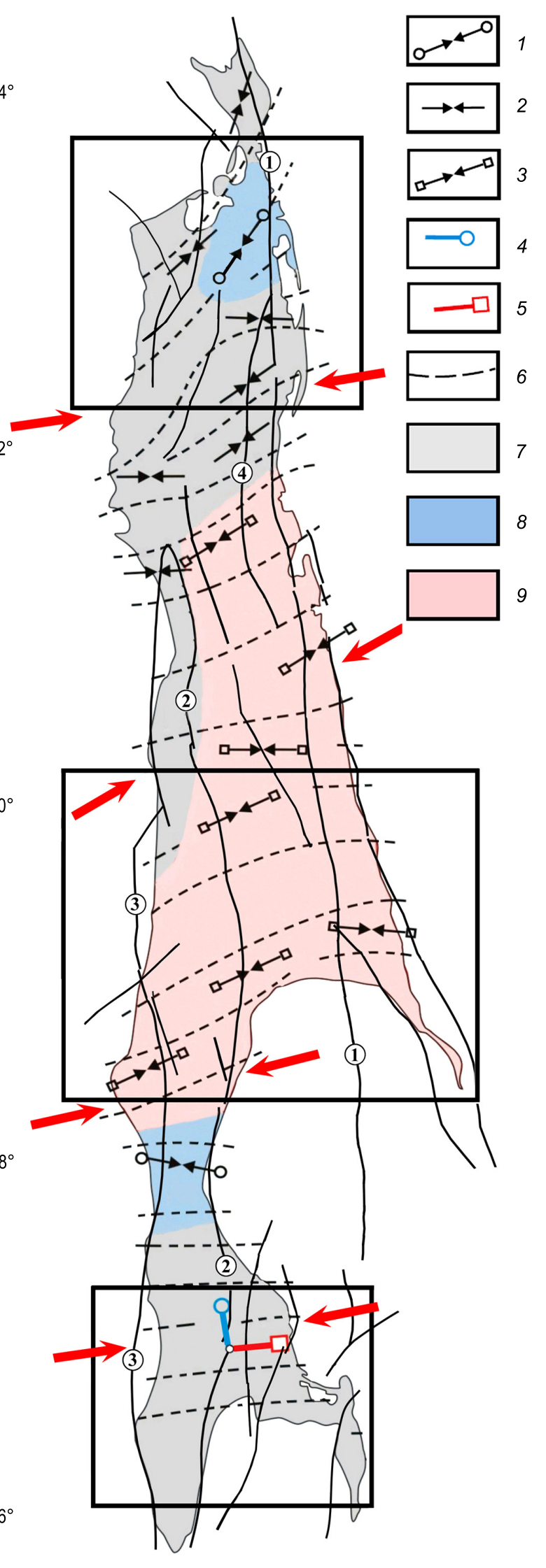


Рис. 1. (a) - карта эпицентров землетрясений о. Сахалин за период 1906-2016 гг. и основные разломы по В.В. Харахинову [Kharakhinov, 2010]. На схеме-врезке приведены границы литосферных плит региона: EU - Евразийской, NA - Североамериканской, PA - Тихоокеанской, АM - Амурской, ОK - Охотской. Стрелками показаны скорости схождения литосферных плит в пределах о. Сахалин относительно Евразии. (б) - схема районирования областей с разной геодинамической обстановкой [Sim et al., 2017a].

1-3 - оси сжатия, восстановленные структурно-геоморфологическим методом в разных геодинамических обстановках: 1 - дополнительного растяжения, 2 - трехосного напряженного состояния, 3 - дополнительного сжатия; 4-5 - оси главных нормальных напряжений, восстановленные методом нахождения общих полей напряжений Южного Сахалина: 4 - растяжения, 5 - сжатия; 6 - траектории осей сжатия; 7-9 - области с геодинамическими обстановками: 7 - трехосного напряженного состояния, 8 растяжения, 9 - сжатия. Направления регионального тензора напряжений сжатия по данным механизмов очагов землетрясений

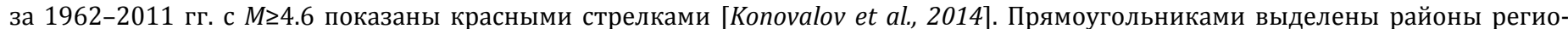
нальных сетей GPS-наблюдений северной, центральной и южной части острова. Основные разломы (цифры в кружках): 1 - Хоккайдо-Сахалинский, 2 - Центрально-Сахалинский, 3 - Западно-Сахалинский, 4 - Верхне-Пильтунский.

Fig. 1. (a) - the Sakhalin Island map showing earthquake epicentres for the period of 1906-2016 and the main faults after [Kharakhinov, 2010]. The inset shows the boundaries of the lithospheric plates: EU - Eurasian, NA - North American, PA Pacific, AM - Amur, OK - Okhotsk. The arrows show the rates of convergence of the lithospheric plates within the Sakhalin Island in relation to Eurasia. (6) - zoning of the areas with different geodynamic settings [Sim et al., 2017a].

1-3 - compression axes reconstructed from the structural-geomorphological data on different geodynamic settings: 1 - additional stretching, 2 - triaxial stress states, 3 - additional compression; 4-5 - axes of the main normal stresses reconstructed by the method of finding common stress fields of the Southern Sakhalin: 4 - stretching, 5 - compression; 6 - trajectories of compression axes; 7-9 - areas of different geodynamic settings: 7 - triaxial stress state, 8 - stretching, 9 - compression. Red arrows show the directions of the regional stress tensor of compression, according to the $M \geq 4.6$ earthquake focal mechanism of the period of 1962-2011 [Konovalov et al., 2014]. Boxed are the observation zones of the regional GPS networks in the northern, central and southern parts of the Sakhalin Island. Faults (circled numbers): 1 - Hokkaido-Sakhalin, 2 - Central Sakhalin, 3 - Western Sakhalin, 4 - Verkhnepiltunsky.

предыдущие эпохи наблюдений. Суточные файлы измерений формировались с 30-секундной дискретностью, общепринятой для геодинамических исследований, и маской возвышения спутников от $5^{\circ}$. Непрерывные наблюдения на пункте YSSK (г. Южно-Сахалинск) выполняются с 1999 г., станция входит в состав международной IGS-сети (International GPS Service). Пункты постоянно действующих GPS/ГЛОНАСС станций OKHA и UGLG организованы в 2009 г. в рамках Комплексной программы ДВО РАН «Современная геодинамика, активные геоструктуры и природные опасности Дальнего Востока России».

Обработка данных осуществлялась с использованием программного обеспечения GAMIT/GLOBK [King, Bock, 2006]. Для связи сетей с общеземной системой координат ITRF2008 (International Terrestrial Reference Frame) [Altamimi et al., 2011] в ежедневные решения были включены 24 станции международной IGS-сети, имеющие длительную временную стабильность. При этом использовались финальные орбиты спутников, представленные IGS, параметры ориентации вращения Земли IERS (International Earth Rotation and Reference Systems Service), таблицы зависимостей фазовых центров антенн, параметров Солнца и Луны и другие материалы, рекомендованные Международной GPS-службой.
Скорости смещений пунктов Сахалинской геодинамической сети вычислены относительно неподвижной Евразии (см. рис. 2, $a, 3, a, 4, a$ ). Использовались 13 опорных IGS-станций, расположенных в стабильных областях Евразийской плиты, остаточные скорости которых не превышают 1 мм/год [Kogan, Steblov, 2008]. Это позволило установить региональные особенности современных движений земной коры районов исследований.

На севере и в центральной части о. Сахалин в период инструментальных GPS-наблюдений не зафиксировано сейсмических событий, способных оказать влияние на скорости пунктов. Наблюдения в центральной части острова начаты спустя два месяца после Углегорского землетрясения 2000 г. На пунктах YS10 и SHBN сети южной части острова (см. рис. 2, $a$ ) использованы результаты наблюдений за период 1999-2005 гг., поскольку на них проявились смещения в результате Невельского землетрясения 2007 г.

Геодинамические GPS-наблюдения на поперечном профиле северной части о. Сахалин и пунктах, контролирующих окрестности Верхне-Пильтунского сейсморазрыва, позволили установить характер деформирования земной поверхности после Нефтегорского землетрясения 1995 г. По направлению с запада на восток происходит постепенное увеличение широтной компоненты скоростей пунктов от 
(a)

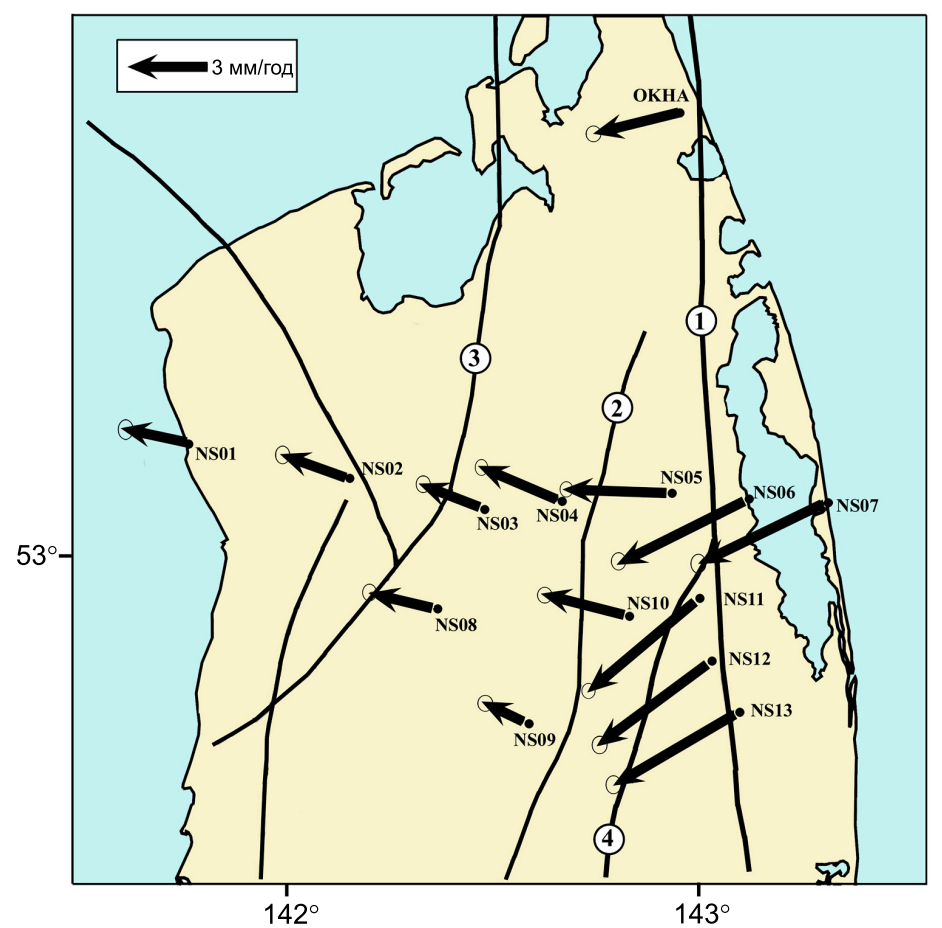

(б)

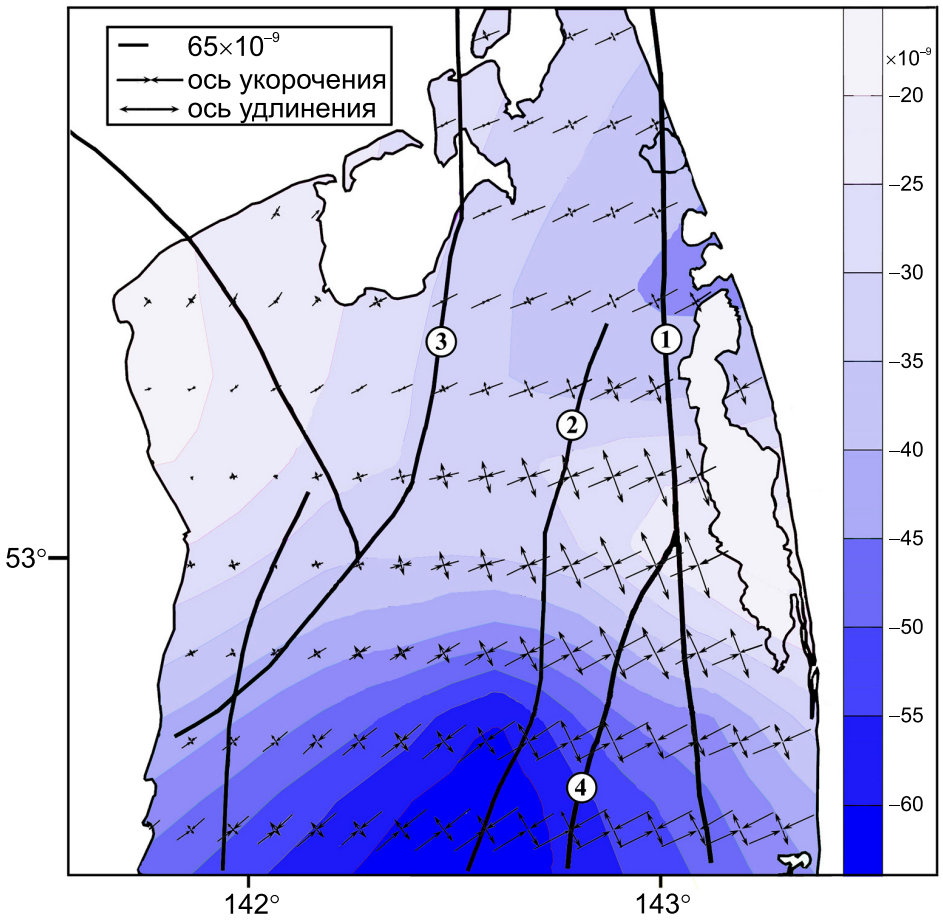

Рис. 2. $(a)$ - горизонтальные скорости GPS-пунктов северной части о. Сахалин относительно Евразийской литосферной плиты за период 2003-2013 гг. (б) - скорости дилатации и горизонтальных деформаций земной поверхности. Цифрами обозначены разломы: 1 - Хоккайдо-Сахалинский, 2 - Гыргыланьинский, 3 - Западно-Байкальский, 4 Верхне-Пильтунский. Здесь и далее: эллипсы ошибок скоростей соответствуют 95\%-ному доверительному интервалу; направления стрелок показывают собственные направления тензора (направления главных осей) деформаций.

Fig. 2. (a) - horizontal velocities at the GPS observation points in the northern part of the Sakhalin island in relation to the Eurasian lithospheric plate for the period of 2003-2013. (б) - velocities of dilatation and horizontal deformation of the earth surface. Faults (circled numbers): 1 - Hokkaido-Sakhalin, 2 - Gyrgylaninsky, 3 - Western Baikal, 4 - Verkhnepiltunsky. Here and in Figs. 3-4, the velocity error ellipses correspond to 95\% confidence interval; arrows show the deformation tensor directions (the directions of the principal axes).

2.0 до 4.7 мм/год. К востоку от Верхне-Пильтунского сейсморазрыва скорости пунктов резко меняют свое субширотное направление на юго-западное, при этом скорость смещения достигает 5.2 мм/год.

В центре и на юге острова скорости пунктов достаточно монотонно возрастают с запада на восток, достигая максимальных значений 6.4 и 10.5 мм/год, соответственно. На юге острова, в отличие от его центральной части, где векторы скоростей имеют $3 Ю 3$ направление, ориентация векторов практически широтная.

Современная кинематика районов исследований свидетельствует о преобладающем сжатии островной суши в субширотном направлении. Такая картина движений соответствует тектоническому режиму зоны конвергенции Евразийской и Североамериканской литосферных плит и находит отражение в направлениях регионального тензора напряжений сжатия по данным механизмов очагов землетрясений [Konovalov et al., 2014] (см. рис. 1).

\section{4. ВЫЧИСЛЕНИЕ СКОРОСТЕЙ ГОРИЗОНТАЛЬНЫХ ДЕФОРМАЦИЙ}

Скорости горизонтальных деформаций земной поверхности о-ва Сахалин вычислены по методике [Teza et al., 2008], реализующей подход модифицированного метода наименьших квадратов [Shen et $a l ., 1996]$. Для расчета в качестве исходных данных использованы горизонтальные скорости смещений пунктов GPS-наблюдений и погрешности их определения, однако следует отметить, что для вычисления скоростей относительных деформаций система отсчета не важна.

Горизонтальную скорость движения в окрестности произвольной точки земной поверхности в условиях малой деформации можно описать с помощью уравнения с двумерным тензором градиента скорости $u_{i}=L_{i j} \Delta x_{j}+U_{i}$, где $u_{i}$ - горизонтальная компонента скорости в точке GPS-наблюдения; $U_{i}-$ константа, соответствующая смещению начала 
(a)

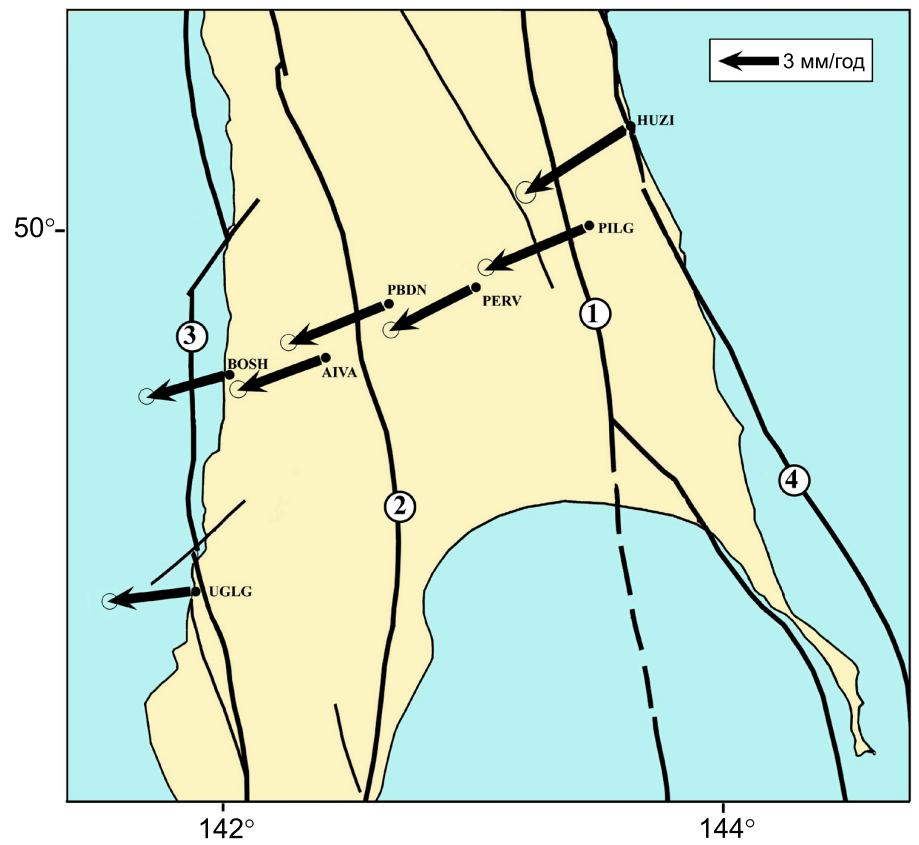

(б)

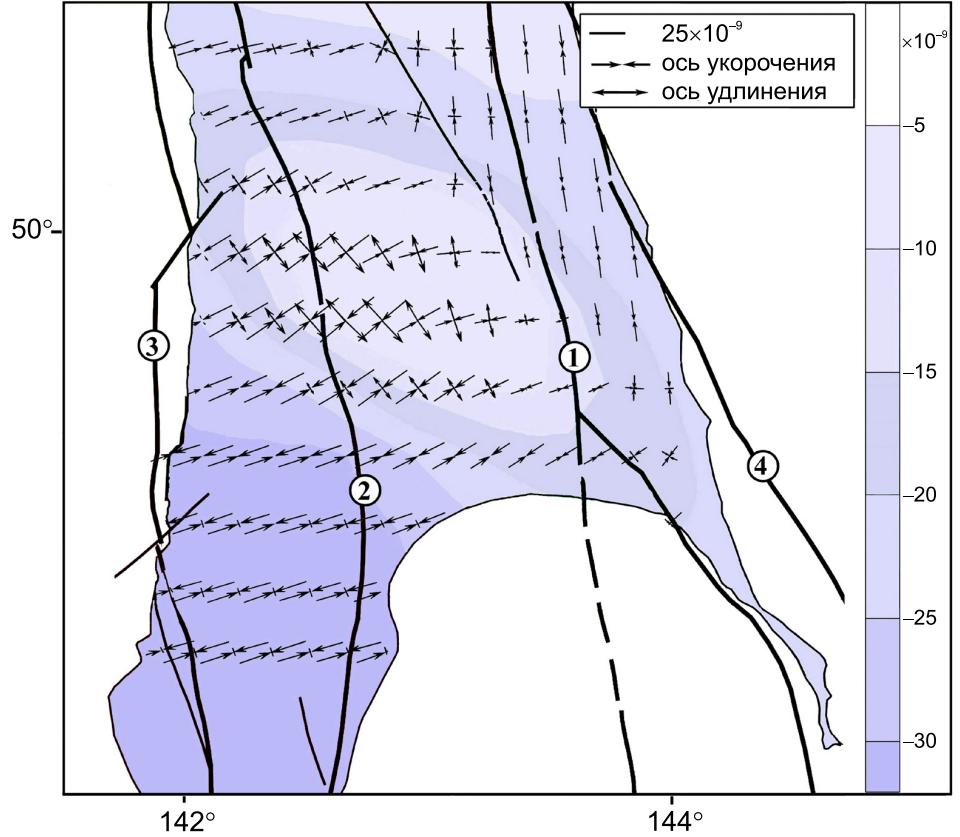

Рис. 3. (a) - горизонтальные скорости GPS-пунктов центральной части о. Сахалин относительно Евразийской литосферной плиты за период 2000-2011 гг. (б) - скорости дилатации и горизонтальных деформаций земной поверхности. Разломы: 1 - Хоккайдо-Сахалинский, 2 - Центрально-Сахалинский, 3 - Западно-Сахалинский, 4 - Пограничный.

Fig. 3. (a) - horizontal velocities at the GPS observation points in the central part of the Sakhalin island in relation to the Eurasian lithospheric plate for the period of 2000-2011. (б) - velocities of dilatation and horizontal deformation of the earth surface. Faults (circled numbers): 1 - Hokkaido-Sakhalin, 2 - Central Sakhalin, 3 - Western Sakhalin, 4 - Pogranichny.

системы отсчета; $\Delta x_{j}$ - бесконечно малые приращения вдоль осей $x, y ; L_{i j}$ - тензор градиента скорости, индекс $i=x, y ; j=x, y$.

Двумерный тензор градиента скорости $L_{i j}$ аддитивно можно разделить на симметричную и кососимметричную части: $L=E+\Omega$ или $L_{i j}=\varepsilon_{i j}+\omega_{i j}=$ $=\left(L_{i j}+L_{j i}\right) / 2+\left(L_{i j}-L_{j i}\right) / 2$, отражающие эффекты деформации и вращения, соответственно.

Диагонализация тензора скорости деформации $E$ приводит к собственным векторам $\overline{v_{k}}$ и собственным значениям $\lambda_{\kappa}$, которые удовлетворяют отношению $E \overline{v_{k}}=\lambda_{k} \overline{v_{k}}(k=1,2)$. Собственные значения представляют собой главные значения тензора скорости деформации, собственные вектора задают главные направления тензора скорости деформации. Наибольшие и наименьшие собственные значения тензора характеризуют максимум и минимум скорости деформации в данной точке и обычно обозначаются как $\mathrm{e}_{\max }$ и $\mathrm{e}_{\min }$.

Решение избыточной системы уравнений методом наименьших квадратов дает величину компонент тензора скорости деформаций и погрешности их определения. Расчет скоростей деформаций выполнялся по узлам регулярной сетки, в каждом узле которой определялась локальная скорость деформации с использованием подходящей страте- гии взвешивания. При этом все доступные наблюдения включались в вычислительную процедуру, но их ошибки масштабировались с помощью весовой функции $f=e^{-d_{i} / d_{0}}$, которая характеризует степень значимости $i$-той станции в зависимости от расстояния до заданной точки $d_{i}, d_{0}$ - масштабный параметр [Shen, Jackson, 2000]. Таким образом, уменьшается вклад точек наблюдения по мере их удаления от узла расчета. В настоящих расчетах параметр $d_{0}$ был принят 30 км, что позволило получить достоверные решения для существующих сетей наблюдений.

На основе полученных собственных значений тензора скорости деформаций в каждой точке расчетной сетки вычислялась скорость плоской деформации (дилатации): $\Delta=\mathrm{e}_{\min }+\mathrm{e}_{\max }$.

\section{5. РЕЗУЛЬТАТЫ ИССЛЕДОВАНИЙ И ИХ ОБСУЖДЕНИЕ}

Анализ пространственного распределения скоростей деформаций на севере, в центральной части и на юге острова свидетельствует о неоднородном характере деформирования земной поверхности (см. рис. 2, б, 3, б, 4, б). В целом, для региона преобладающим режимом является региональное 


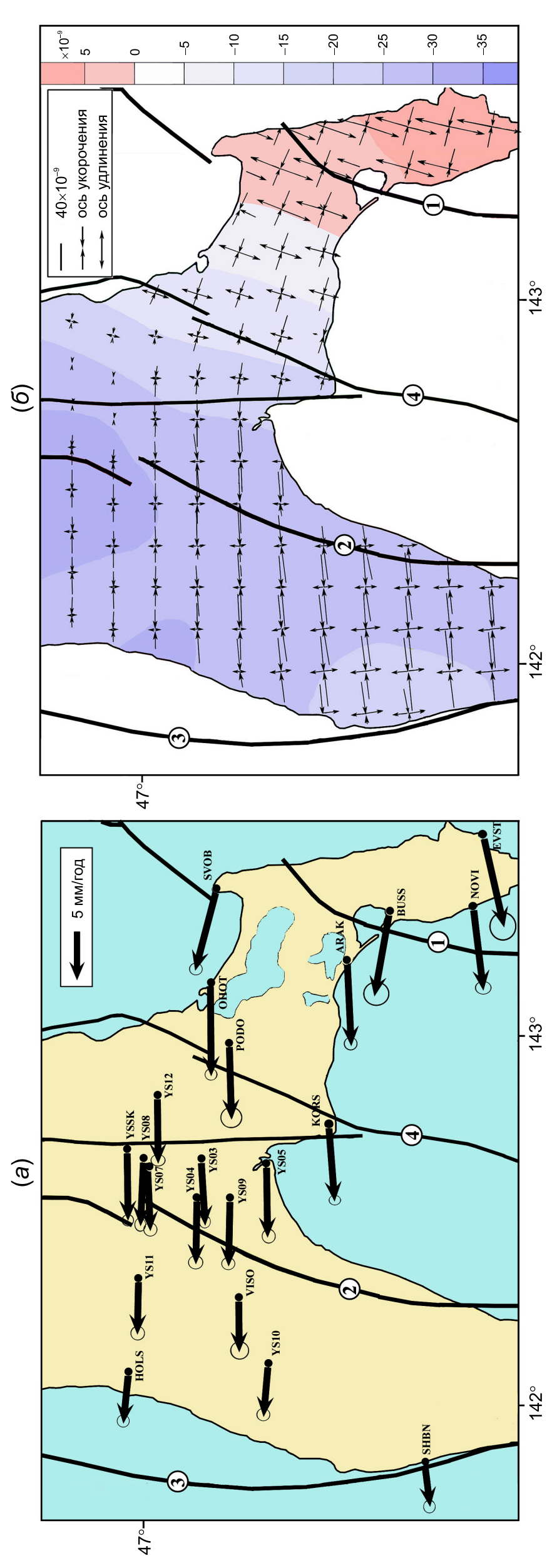


сжатие островной суши в субширотном направлении, однако оно меняется от района к району.

\section{1. ДЕФОРМАЦИИ ЗЕМНОЙ ПОВЕРХНОСТИ СЕВЕРА О. САХАЛИН}

Территория северной части острова характеризуется преобладанием условий горизонтального сжатия земной поверхности СВ-ЮЗ направления (см. рис. 2, б). Максимальные скорости деформаций до $|130| \times 10^{-9}$ в год проявляются в восточной части района. В этой области величины скоростей сжатия (укорочения) и растяжения (удлинения) практически сопоставимы (скорость дилатации не превышает $-30 \times 10^{-9}$ в год), что свидетельствует о наличии правостороннего сдвига в окрестности Хоккайдо-Сахалинского разлома и к западу от него. Современный характер деформирования земной поверхности в районе этого разлома подтверждает его взбросо-сдвиговую кинематику, установленную по геологическим данным. Наиболее интенсивное сокращение земной поверхности (скорость дилатации до $-70 \times 10^{-9}$ в год) наблюдается между Западно-Байкальским разломом и Верхне-Пильтунским сейсморазрывом и, по-видимому, связано с продолжающимся накоплением упругих деформаций после Нефтегорского землетрясения.

Для этой части острова наблюдается прямая зависимость между скоростью современных горизонтальных деформаций и сейсмичностью. Высокие скорости деформаций земной поверхности приурочены к району повышенной сейсмической активности последних лет, тогда как область низких скоростей коррелирует с зоной слабой и разреженной сейсмичности (см. рис. $1, a$ ).

Направление скоростей деформаций Северного Сахалина в целом согласуется с ориентировкой осей напряжений сжатия и растяжения, восстановленных методом катакластического анализа механизмов очагов региональных землетрясений [ $\mathrm{Sim}$ et al., 2017b; Tataurova, 2015]. Отличительной особенностью результатов настоящих исследований является отсутствие области растяжений (положительных значений скорости дилатации), которая выявлена при оценке новейшей геодинамической обстановки острова [Sim et al., 2017a] (см. рис. 1, б).

\section{2. ДЕФОРМАЦИИ ЗЕМНОЙ ПОВЕРХНОСТИ ЦЕНТРАЛЬНОЙ ЧАСТИ О. САХАЛИН}

Центральная часть острова характеризуется весьма неоднородным характером деформирования с преобладанием условий одноосного сжатия земной поверхности (см. рис. 3, б). Здесь выделяются зоны с различной геодинамической обстановкой: субмеридиональная ориентация деформаций сжатия на востоке сменяется сжатием Ю3-СВ направлений на западном крыле ХоккайдоСахалинского разлома. Наиболее интенсивное сокращение земной поверхности в направлении ВСВЗЮЗ происходит в юго-западной части района исследований, где скорости дилатации достигают $(-25 \ldots-30) \times 10^{-9}$ в год.

Максимальные скорости горизонтальных деформаций (до $|50| \times 10^{-9}$ в год) приурочены к зоне Центрально-Сахалинского разлома и его ближайшим окрестностям. Здесь скорости деформаций сжатия и растяжения имеют практически одинаковую величину (скорость дилатации не превышает $-5 \times 10^{-9}$ в год) и указывают на взбросо-сдвиговую кинематику разлома в центральной части острова. Вместе с тем высоким скоростям деформаций соответствует повышенный уровень современной сейсмичности в окрестностях Западно- и Центрально-Сахалинского разломов (см. рис. $1, a$ ).

Неоднородный характер деформирования центральной части о. Сахалин в некоторой мере может являться следствием малого количества пунктов GPS-наблюдений. Недостаток исходных данных увеличивает погрешность расчетов. Однако, за исключением восточной части района, направление осей деформаций, в целом, согласуется с неотектонической обстановкой (см. рис. 1, б) [Sim et al., $2017 a, 2017 b]$.

\section{3. ДЕФОРМАЦИИ ЗЕМНОЙ ПОВЕРХНОСТИ ЮГА О. САХАЛИН}

На юге о. Сахалин, наряду с доминирующим сжатием островной суши, которое в скоростях деформаций сжатия земной поверхности достигает значений $-70 \times 10^{-9}$ в год, в восточной части выделяется область растяжения со скоростями до $80 \times 10^{-9}$ в год (рис. 4, б). Изменение деформационного состояния происходит в окрестности Сусунайского разлома. Преобладающим режимом деформирования восточной части района становится растяжение земной поверхности, которое отчетливо картируется положительными скоростями дилатации до $\sim 10 \times 10^{-9}$ в год.

Максимальное накопление деформаций субширотного сжатия происходит в зоне ЦентральноСахалинского разлома и к западу от него, что отражает кинематику разлома, которая в этой части острова характеризуется взбросо-надвиговой природой. Область высоких скоростей дилатации (до $(-30 \ldots-40) \times 10^{-9}$ в год) коррелирует с районом повышенной сейсмической активности, в то время как зона растяжений является практически асейсмичной (см. рис. $1, a$ ).

Направления скоростей деформаций западной части района находят отражение в устойчивых ориентировках осей напряжений сжатия и растяжения [Sim et al., 2017a, 2017b], а также согласуются 
с проекцией на горизонтальную плоскость главных осей деформаций укорочения, восстановленных по сейсмологическим данным [Tataurova, 2015]. Отличительной особенностью в геодинамической обстановке юга о. Сахалин является область растяжений к востоку от Сусунайского разлома, которая ранее не была выявлена по результатам реконструкции неотектонических напряжений (см. рис. 1, б).

\section{6. ЗАКЛЮЧЕНИЕ}

На основе межсейсмических скоростей GPSпунктов Сахалинской геодинамической сети выполнено моделирование деформированного состояния земной поверхности северной, центральной и южной части о. Сахалин. Результаты исследований выявили сложную картину современных горизонтальных деформаций в окрестностях главных субмеридиональных разломов острова. Территория островной суши характеризуется преобладанием условий горизонтального сжатия земной поверхности, что соответствует современному тектоническому режиму региона. Однако пространственное распределение деформаций земной поверхности неоднородно и изменяется от района к району.

Сокращение земной коры острова происходит в основном в субширотном и ЮЗ-СВ направлениях. Максимальные скорости горизонтальных деформаций сжатия до $|130| \times 10^{-9}$ в год наблюдаются на севере острова, где между Западно-Байкальским разломом и Верхне-Пильтунским сейсморазрывом дилатация достигает $-70 \times 10^{-9}$ в год, в то время как в центральной и южной части она не превышает $-40 \times 10^{-9}$ в год.

Наряду с преобладанием условий горизонтального сжатия, на севере и в центральной части острова выделяются области интенсивных деформа- ций правостороннего сдвига, характерные, соответственно, для зон Хоккайдо-Сахалинского и Центрально-Сахалинского разломов. Резкое изменение деформированного состояния происходит на юге острова к востоку от Сусунайского разлома: преобладающим режимом деформирования земной поверхности здесь становится растяжение ВСВ-ЗЮЗ направления со скоростью дилатации до $\sim 10 \times 10^{-9}$ в год.

Региональная геодинамическая обстановка находит отражение в сейсмичности острова. В районах интенсивного деформирования земной поверхности проявляется повышенная сейсмическая активность последних лет, тогда как области низких скоростей деформаций коррелируют с зонами слабой и разреженной сейсмичности.

Выполненные исследования деформированного состояния земной поверхности о. Сахалин в целом согласуются с ориентацией современного поля тектонических напряжений. Отличительной особенностью полученных результатов является отсутствие области растяжений (положительных значений скорости дилатации) на севере острова и их наличие на юге. Нетипичные для геодинамической обстановки области растяжения и деформации сдвига свидетельствуют о сложном геологическом строении острова и, скорее всего, являются откликом среды на общее сжатие в результате схождения Евразийской (Амурской) и Североамериканской (Охотской) литосферных плит.

\section{7. БЛАГОДАРНОСТИ}

Работа выполнена в рамках государственного задания ИМГиГ ДВО РАН, а также при частичной поддержке Комплексной программой фундаментальных научных исследований ДВО РАН «Дальний Восток» (проект № 18-5-024).

\section{8. ЛИТЕРАTУРA / REFERENCES}

Altamimi Z., Collilieux X., Métivier L., 2011. ITRF2008: an improved solution of the international terrestrial reference frame. Journal of Geodesy 85 (8), 457-473. https://doi.org/10.1007/s00190-011-0444-4.

Altamimi Z., Sillard P., Boucher C., 2002. ITRF2000: A new release of the International Terrestrial Reference Frame for earth science applications. Journal of Geophysical Research: Solid Earth 107 (B10), 2214. https://doi.org/10.1029/ 2001JB000561.

Apel E.V., Burgmann R., Steblov G., Vasilenko N., King R., Prytkov A., 2006. Independent active microplate tectonics of Northeast Asia from GPS velocities and block modeling. Geophysical Research Letters 33 (11), L11303. https:// doi.org/10.1029/2006GL026077.

Ashurkov S.V., San'kov V.A., Serov M.A., Luk'yanov P.Yu., Grib N.N., Bordonskii G.S., Dembelov M.G., 2016. Evaluation of present-day deformations in the Amurian Plate and its surroundings, based on GPS data. Russian Geology and Geophysics 57 (11), 1626-1634. https://doi.org/10.1016/j.rgg.2016.10.008.

Chapman M.E., Solomon S.C., 1976. North American-Eurasian plate boundary in Northeast Asia. Journal of Geophysical Research 81 (5), 921-930. https://doi.org/10.1029/jb081i005p00921.

DeMets D.C., Gordon R.G., Argus D.F., 2010. Geologically current plate motions. Geophysical Journal International 181 (1), 1-80. https://doi.org/10.1111/j.1365-246x.2009.04491.x. 
Federal Research Center "Geophysical Survey of Russian Academy of Sciences", Catalogs, 2017. Available from: http:// www.ceme.gsras.ru/cgi-bin/new/catalog.pl (last accessed 15.11.2017).

Kharakhinov V.V., 2010. Oil-Gas Geology of the Sakhalin Region. Nauchnyy Mir, Moscow, 276 p. (in Russian) [Xapaxuнов B.B. Нефтегазовая геология Сахалинского региона. М.: Научный мир, 2010. 276 с.].

King R.W., Bock Y., 2006. Documentation for the GAMIT GPS Software Analysis Version 10.3. Massachusetts Institute of Technology (MIT), $182 \mathrm{p}$.

Kogan M.G., Steblov G.M., 2008. Current global plate kinematics from GPS (1995-2007) with the plate-consistent reference frame. Journal of Geophysical Research: Solid Earth 113 (B4), B04416. https://doi.org/10.1029/2007 JB005353.

Konovalov A.V., Nagornyh T.V., Safonov D.A., 2014. Recent Study of Earthquake Source Mechanisms in Sakhalin. Dal'nauka, Vladivostok, 252 p. (in Russian) [Коновалов А.В., Нагорных Т.В., Сафонов Д.А. Современные исследования механизмов очагов землетрясений о. Сахалин. Владивосток: Наука, 2014. 252 с.].

Konovalov A.V., Stepnov A.A., Gavrilov A.V., Manaychev K.A., Sychov A.S., Klachkov V.A., Saburov M.S., 2016. Regional seismicity behavior in the Northern Sakhalin in connection to offshore oil and gas fields production. History of Science and Engineering (6), 63-71 (in Russian) [Коновалов А.В., Степнов А.А., Гаврилов А.В., Манайчев К.А., Сычев А.С., Клачков В.A., Сабуров М.С. Особенности региональной сейсмичности на севере о. Сахалин в связи с промышленным освоением месторождений нефти и газа на шельфе // История науки и техники. 2016. № 6. C. 63-71].

Melnikov O.A., 1977. On the relationship between the geological structure and the seismicity of Sakhalin. In: Seismic zoning of Sakhalin. Far Eastern Scientific Center of the USSR Acad. Sci., Vladivostok, p. 46-51. (in Russian) [Мельников O.A. О взаимосвязи геологического строения и сейсмичности Сахалина // Сейсмическое районирование Сахалина. Владивосток: ДВНЦ АН СССР, 1977. С. 46-51].

Poplavskaya L.N., Ivashchenko A.I., Oskorbin L.S., Nagornykh T.V., Permikin Yu.Yu., Poplavsky A.A., Fokina T.A., Kim Ch.U., Kraeva N.V., Rudik M.I., Safonov D.A., Doroshkevich E.N., Parshina I.A., Zherdeva O.A., 2006. Regional Catalog of Sakhalin Earthquakes 1905-2005. IMGG FEB RAS, Yuzhno-Sakhalinsk, 103 p. (in Russian) [Поплавская Л.Н., Иващенко А.И., Оскорбин Л.С., Нагорных Т.В., Пермикин Ю.Ю., Поплавский А.А., Фокина Т.А., Ким Ч.У., Краева Н.В., Рудик М.И., Сафонов Д.А., Дорошкевич Е.Н., Паршина И.А., Жердева О.А. Региональный каталог землетрясений острова Сахалин, 1905-2005 гг. Южно-Сахалинск: ИМГиГ ДВО РАН, 2006. 103 с.].

Shen Z.K., Jackson D.D., 2000. Optimal estimation of geodetic strain rates from GPS data. EOS, Transactions of the American Geophysical Union 81 (19), S406.

Shen Z.K., Jackson D.D., Ge B.X., 1996. Crustal deformation across and beyond the Los Angeles basin from geodetic measurements. Journal of Geophysical Research: Solid Earth 101 (B12), 27957-27980. https://doi.org/10.1029/ 96jb02544.

Sim L.A., Bogomolov L.M., Bryantseva G.V., Savvichev P.A., 2017a. Neotectonics and tectonic stresses of the Sakhalin Island. Geodynamics \& Tectonophysics 8 (1), 181-202 (in Russian) [Сим Л.А., Богомолов Л.м., Брянцева Г.В., Саввичев П.А. Неотектоника и тектонические напряжения острова Сахалин // Геодинамика и тектонофизика. 2017. T. 8. № 1. C. 181-202]. https://doi.org/10.5800/GT-2017-8-1-0237.

Sim L.A., Bryantseva G.V., Savvichev P.A., Kamenev P.A., 2017b. Patterns of transition zone between Eurasian and North American plates (by example of stressed state of the Sakhalin Island). Geosystems of Transition Zone 1 (1), 3-22 (in Russian) [Сим Л.А., Брянцева Г.В., Савичев П.А., Каменев П.А. Особенности переходной зоны между Евразийской и Северо-Американской литосферными плитами (на примере напряженного состояния о-ва Сахалин) // Геосистемы переходных зон. 2017. Т. 1. № 1. С. 3-22].

Streltsov M.I., Kozhurin A.I., 2002. Active Faults and Earthquake of Sakhalin (Aprelovsky Active Fault, the Results of Trenching). IMGG FEB RAS, Yuzhno-Sakhalinsk, 4 p. (in Russian] [Стрельцов М.И., Кожурин А.И. Активные разломы и катастрофические землетрясения Сахалина (Апреловский активный разлом, результаты тренченга). Южно-Сахалинск: ИМГиГ ДВО РАН, 2002. 4 с.].

Tataurova A.A., 2015. Stress and strain fields based on data on crustal earthquake mechanisms in Sakhalin Island. Bulletin of Kamchatka Regional Association Education-Science Centre. Earth Sciences (3), 92-101 (in Russian) [Taтаурова А.А. Поля напряжений и деформации по данным механизмов коровых землетрясений о. Сахалин // Вестник КРАУНЦ. Науки о Земле. 2015. № 3. С. 92-101].

Teza G., Pesci A., Galgaro A., 2008. Grid_strain and grid_strain3: Software packages for strain field computation in 2D and 3D environments. Computers \& Geosciences 34 (9), 1142-1153. https://doi.org/10.1016/j.cageo.2007.07.006.

Vasilenko N.F., Prytkov A.S., 2012. GPS-based modeling of the interaction between the lithospheric plates in Sakhalin. Russian Journal of Pacific Geology 6 (1), 35-41. https://doi.org/10.1134/s1819714012010137.

Vasilenko N.F., Prytkov A.S., Saprygin S.M., 2016. Geodynamical GPS/GLONASS investigations in the Sakhalin-Kuril region. History of Science and Engineering (6), 72-80 (in Russian) [Василенко Н.Ф., Прытков А.С., Сапрыгин С.М. Геодинамические GPS/ГЛОНАСС исследования в Сахалин-Курильском регионе // История науки и техники. 2016. № 6. С. 72-80].

Zonenshain L.P., Savostin L.A., 1981. Geodynamics of the Baikal rift zone and plate tectonics of Asia. Tectonophysics 76 (1-2), 1-45. https://doi.org/10.1016/0040-1951(81)90251-1. 


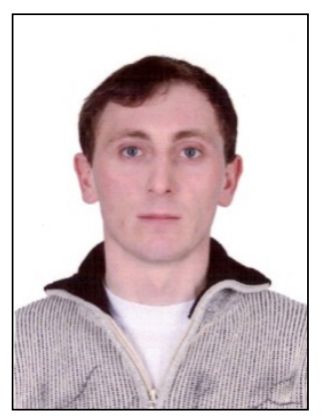

Александр Сергеевич Прытков, канд. физ.-мат. наук, в.н.с.

Институт морской геологии и геофизики ДВО РАН

693022, Южно-Сахалинск, ул. Науки, 1Б, Россия

e-mail: a.prytkov@imgg.ru

Alexander S. Prytkov, Candidate of Physics and Mathematics, Lead Researcher Institute of Marine Geology and Geophysics, Far East Branch of RAS

1B Nauka street, Yuzhno-Sakhalinsk 693022, Russia

e-mail: a.prytkov@imgg.ru

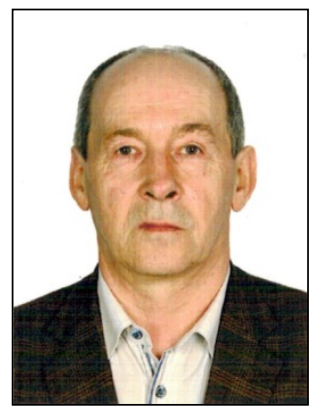

Николай Федорович Василенко, канд. техн. наук, в.н.с.

Институт морской геологии и геофизики ДВО РАН

693022, Южно-Сахалинск, ул. Науки, 1Б, Россия

e-mail: n.vasilenko@imgg.ru

Nikolay F. Vasilenko, Candidate of Technical Sciences, Lead Researcher Institute of Marine Geology and Geophysics, Far East Branch of RAS

1B Nauka street, Yuzhno-Sakhalinsk 693022, Russia

e-mail: n.vasilenko@imgg.ru 